\title{
Antioxidant Effect of Nonalcoholic Syrups Based on Wild-Growing Herbal Raw Material
}

\author{
Lyudmila Aleksandrovna Tekuteva ${ }^{1}$, Oksana Mikhailovna Son ${ }^{1 *}$, Evgeniia Sergeevna Fishchenko', Victoriya Ivanovna Bobchenko ${ }^{1}$ \\ and Natalya Vasilievna Plaksen ${ }^{2}$ \\ ${ }^{1}$ Department of Commodity and Examination of Goods, School of Economics and Management, Far Eastern Federal University, Vladivostok, Russia \\ ${ }^{2}$ Department of Pharmacy, Pacific State Medical University (formerly Vladivostok State Medical University), Vladivostok, Russia
}

${ }^{*}$ Corresponding author: Son OM, Department of Commodity and Examination of Goods, School of Economics and Management, Far Eastern Federal University, Vladivostok, Russia; E-mail: oksana_son@bk.ru

Received: Mar 21, 2016; Accepted: Jun 7, 2016; Published: Aug 27, 2016

Copyright: () 2016 Tekuteva et al. This is an open-access article distributed under the terms of the Creative Commons Attribution License, which permits unrestricted use, distribution, and reproduction in any medium, provided the original author and source are credited.

\begin{abstract}
In the experiment, the rat was used to estimate the antioxidant effect of syrups based on vegetable raw materials. Simulated stress, determines the relative weight of the liver, adrenal glands, spleen, thymus, counted the number of ulcerations in the gastric mucosa was studied lipid peroxidation was determined by cumulative antiradical activity [1]. Discovered and proved the antioxidant effect.
\end{abstract}

Keywords: Rats; Hepatotoxin; Herbal syrups

\section{Introduction}

Solving the problem of adaptation of humans and animals to inadequate environmental conditions can only be based on a thorough understanding of the mechanisms of resistance to adverse environmental factors and, in particular, the factors that enhance the stability of membrane lipids to the damaging effects of oxygen radicals [2]. It is known that drugs (group of adaptogens) increasing the body's resistance to a wide range of adverse factors in the external and internal environment and having an antioxidant effect help stabilize the lipid peroxidation of biomembranes in conditions of prolonged cold stress, administration of carbon tetrachloride, etc. [4]. To date, numerous studies have proven antioxidant activity of polyphenolic compounds of plant origin, the most important of which in this respect are the flavonoids and anthocyanins [7-10.] The possibility of wide application of polyphenolic compounds as antioxidants determines the relevance of the search for new, inexpensive, and available raw material sources. The harmful effects of free radicals in the case of oxidative stress can be reduced by regular consumption of certain foods and beverages, pharmaceuticals, and biologically active additives (BAA) with antioxidantactivity.

\section{Methods}

Studies were performed on 30th August on rats of both sexes weighing 220-290 gm contained in natural light regime and fed standard vivarium diet; the vivarium contained five to six individuals in special plastic cages on wood chips bedding with free access to food and water. We developed a range of syrups with increased physiological values of native raw materials with low sugar content [15], with the following assortment: recipe No. 1 (Altai bouquet balm). The composition was as follows $[16,17,18]$ : plant extracts of St. John's wort herb, licorice root, root Hedysarum tea, rose hips, grass meadow geranium, chaga mushroom, sugar syrup, citric acid (acidifier), potassium sorbate (preservative), and sodium benzoate (preservative) [19,20,21]

The composition of recipe No. 2 was as follows: goji berry (powder), carrageenan (thickener), citric acid (acidifier), sugar syrup, potassium sorbate (preservative), and sodium benzoate (preservative).
The following animal groups were formed: the experimental group No. 1 received the recipe No. 1 (test solution); experimental group No. 2 got syrup formulation No. 2 (test solution); control group No. 1 received no active substances - control solution with sugar syrup, citric acid (acidifier), potassium sorbate (preservative), and sodium benzoate (preservative); control group No. 2 received active ingredientscarrageenan control solution (thickener), citric acid (acidifier), sugar syrup, potassium sorbate (preservative), and sodium benzoate (preservative); the intact group was fed the standard vivarium diet.

Under the influence of unfavorable factors, such as foreign chemicals, the concentration of oxyradicals increases sharply and under certain conditions may exceed the ability of the protective antioxidant system to withstand the ravages of these reactive molecules [22-24]. Carbon tetrachloride $\left(\mathrm{CCI}_{4}\right)$ easily metabolizes in the active trichloromethyl radical $\left(\mathrm{CCI}_{3}\right)$ and initiates a cascade of radical reaction initiators. For this purpose, rats were injected $4 \mathrm{ml} / \mathrm{kg}$ of carbon tetrachloride in a $50 \%$ solution in olive oil once by gavage (3). Animals received syrups by gavage, prophylactically five days prior to the injection of hepatotoxin and free days after intoxication within ten days of the experimental rats were injected syrups. The recommended dose of syrups is $2.8 \mathrm{ml} / \mathrm{kg}$ per day $[25,26]$. The test substances were injected $1 \mathrm{~h}$ prior to the injection of $\mathrm{CCl}_{4}$.

Work was executed in compliance with all regulations and international recommendations of the European Convention for the Protection of Vertebrate Animals used for experimental studies. One day after the last injection of hepatotoxin, animals were excluded from the experiment with the use of light ether anesthesia. The effectiveness of the therapy drug under study was judged by the following tests:

1. Specific liver weight (liver weight in $\mathrm{mg}$ in relation to body weight per g), which characterizes the degree of inflammation in the body [3].

2. Study of lipid peroxidation (LPO) liver malondialdehyde (MDA) - a product of oxidative degradation of fatty acids by a color reaction with 2-thiobarbituric acid [13]. Measurements were performed with a spectrophotometer Shimadzu UV-1650PC.

3. Assessment of integral antiradical activity (IAA) of antioxidants carried by their ability to inhibit the oxidation of ABTS 
by peroxyl and alkoxyl radicals formed by thermal (378C) decomposition of ABAP (2, 29-azobis (2-aminopropane) hydrochloride) [12]. Measurements were performed on a spectrophotometer Shimadzu UV-2550 with a thermostated cell.

4. Determination of the stress protective activity of syrups by sixpoint scale [5].

The results obtained were subjected to statistical analysis using Student's t test.

\section{Results and Discussion}

Under the influence of unfavorable factors, such as foreign chemicals, the concentration of oxyradicals increases sharply and under certain conditions may exceed the ability of the protective antioxidant system to withstand the ravages of these reactive molecules. Carbon tetrachloride $\left(\mathrm{CC}_{4}\right)$ is readily metabolized into the active trichloromethyl radical $\left(\mathrm{CCl}_{3}\right)$ and triggers a cascade of radicalinitiating reactions. As it is known, carbon tetrachloride that is converted with the cytochrome $\mathrm{P}-450$ in free radicals and electrophilic intermediates is aggressive hepatotoxin.

On the injection of $\mathrm{CC}_{4}$, the liver of animals reacted by increasing the relative weight - one of the first informative indicators of intoxication. The animals of the control groups showed a statistically significant increase in liver weights at $28-29 \%$ as compared to intact rats. In the experimental group, the relative liver weight compared with that of the control group decreased by $11 \%$, indicating a lower severity of hepatitis (Table1).

In acute $\mathrm{CC}_{4}$ hepatitis, the severity of antioxidant protection reduced and lipid peroxidation progressed in parallel. In the lipid

\begin{tabular}{|l|l|l|l|l|}
\hline Numbers & $\begin{array}{c}\text { Relative } \\
\text { Group of } \\
\text { animals }\end{array}$ & $\begin{array}{l}\text { liver weight } \\
\text { (mg/g body } \\
\text { weight) }\end{array}$ & $\begin{array}{c}\text { MDA (nmol/g } \\
\text { wet weight) }\end{array}$ & $\begin{array}{l}\text { IAA (mol/g } \\
\text { wet weight) }\end{array}$ \\
\hline 1 & Intact & 22.762 .0 & 7.9760 .96 & 4.5060 .43 \\
\hline 2 & Control No. 1 & $29.162 .5^{\star}$ & $14.1560 .84^{*}$ & 3.4960 .31 \\
\hline 3 & Control No. 2 & $29.462 .6^{*}$ & $23.3060 .71^{*}$ & $2.5460 .17^{*}$ \\
\hline 4 & $\begin{array}{c}\text { Experience } \\
\text { No. } 1\end{array}$ & 26.062 .1 & $13.0860 .39^{*}$ & 3.6760 .22 \\
\hline 5 & $\begin{array}{c}\text { Experience } \\
\text { No. 2 }\end{array}$ & 25.862 .3 & $10.8360 .54^{* *}$ & 3.6960 .13 \\
\hline
\end{tabular}

$p \square 0.05^{*}$ compared to intact group.

$p \square 0.05^{* *}$ compared to the control.

Table 1: Effect of syrups on the relative weight of liver, MDA content, and antiradical activity of the integrated index (IAA) in homogenates of rat liver in experimental hepatitis (M $6 \mathrm{~m}$ ) extracts of liver homogenates, the amount of MDA increased. Indicator of antiradical protection (IAA) decreased by $55 \%$ in the control group number 2 and $23 \%$ in the control group number 1 . In the experimental group treated by syrup number 1 after toxin injection IAA decreased by $19 \%$; in the test group number 2 , by $18 \%$. The level of MDA in control group number 2 compared to the intact group was increased by three times, and in control group number 1 , no strong changes were recorded-peroxidation product content increased by 1.8 times. In the groups of animals treated with syrups, similar changes occurred in the scorecard "total antiradical system," but did not reach the physiological values (Table1).

Syrup injection before and after exposure to carbon tetrachloride has a protective effect, which manifests itself in preventing partial involution lymphoid organs, reducing by half the number of hemorrhages and ulcerations in the gastric mucosa. In the group of animals treated with the formulation number 1, stress-protective activity was three points higher than the corresponding activity in the control group. In the group of animals treated with the formulation number 2, this difference was four points (Table 2).

The drug is considered active if the difference in the scoring of points in the control and experimental groups is more than two points [5].

Under the action of the control formulations without herbs, hepatotoxin after injection showed a significant decrease in IAA and increase in the concentration of MDA - the product of oxidative degradation of fatty acids, and the reduction of antioxidant activity was greater in the control number 2 , the formulation of which included the thickening agent carrageenan. Carrageenan (E407) is a natural gelling agent obtained during the processing of red seaweed by extraction and followed by purification from impurities [10].

Syrup 1 exerts a significant number of stress-protective effects that appear by reducing the size of the adrenal glands and the intensity of the involution of the thymus and spleen. In total, stressing of the body decreased from eleven to eight points (Table 2).

Complex composition of the syrup number 1 is making it difficult to analyze the activity of each component (lack of syrups with complex composition)

Syrup number 2, containing powdered goji berries, significantly reduced the level of peroxidation products (MDA) compared with the control number 1 (Table 1); adrenal hypertrophy was $25 \%$ relative to the control and $42 \%$ relative to the norm; involutions of the thymus, 80 and $46 \%$, respectively. Stressing of the body decreased from sixteen to twelve points (see Table 2).

\begin{tabular}{|c|c|c|c|c|c|c|c|c|c|c|c|c|}
\hline \multirow[b]{2}{*}{$\begin{array}{l}\text { Animal } \\
\text { groups }\end{array}$} & \multicolumn{3}{|c|}{ Adrenal gland } & \multicolumn{3}{|c|}{ Thymus } & \multicolumn{3}{|c|}{ Spleen } & \multicolumn{2}{|c|}{ Stomach ulcers } & \multirow[b]{2}{*}{ Score } \\
\hline & $\begin{array}{l}\text { Weight } \\
\mathrm{mg} / \mathrm{g} \text { body } \\
\text { weight }\end{array}$ & $\%$ & Point & $\begin{array}{l}\text { Weight } \\
\text { mg/g body } \\
\text { weight }\end{array}$ & $\%$ & Point & $\begin{array}{l}\text { Weight } \\
\text { mg/g body } \\
\text { weight }\end{array}$ & $\%$ & Point & Number & Point & \\
\hline Intact & 0.1260 .006 & 100 & 0 & 0.9260 .08 & 100 & 0 & 3.660 .2 & 100 & 0 & 0 & 0 & 0 \\
\hline Control No. 1 & 0.1660 .01 & 133 & 3 & 0.7760 .06 & 84 & 2 & 3.360 .5 & 92 & 1 & 7 & 5 & 11 \\
\hline Control No. 2 & 0.1760 .01 & 142 & 4 & 0.4260 .03 & 46 & 5 & 2.760 .3 & 75 & 2 & 8 & 5 & 16 \\
\hline $\begin{array}{l}\text { Experience } \\
\text { No. } 1\end{array}$ & 0.1360 .02 & 108 & 1 & 0.7760 .07 & 84 & 2 & 3.260 .3 & 89 & 1 & 4 & 4 & 8 \\
\hline $\begin{array}{l}\text { Experience } \\
\text { No. } 2\end{array}$ & 0.1560 .02 & 125 & 2 & 0.7460 .07 & 80 & 2 & 2.660 .4 & 72 & 3 & 5 & 5 & 12 \\
\hline
\end{tabular}

Table 2: Effect of syrups on the change in mass of organs (adrenal, thymus, spleen) and the number of ulcerations of the gastric mucosa of rats under the action of $\mathrm{CCl}_{4}, \mathrm{M} 6 \mathrm{~m}$ 
Citation: Tekuteva LA, Son OM, Fishchenko ES, Bobchenko VI, Plaksen NV (2016) Antioxidant Effect of Nonalcoholic Syrups Based on Wild-Growing Herbal Raw Material. Biol Med (Aligarh) 8: 328. doi:10.4172/0974-8369.1000328.

Page 3 of 3

\section{Conclusions}

Thus, by studying the state of lipid peroxidation and IAA in the liver of animals exposed to a hepatotoxic agent — carbon tetrachloride, the presence of antioxidant activity and a pronounced stress-protective action in syrups No. 1 and No. 2 were found. The experimental results show a decrease in the intensity of free-radical oxidation with the injection of herbal remedies in the form of syrups, which is associated with the presence of a complex of biologically active substances that are part of the test plants. In particular, goji berries (Lycium barbarum) contain essential polysaccharides LBP-1, LBP-2, LBP-3, and LBP-4 that are no longer present in any food product, vitamins, 18 amino acids, and 21 minerals (including iron, zinc, iodine). Vitamin $\mathrm{C}$ in the berries is more than in oranges [27-30].

Present in plants, flavonoids inhibit the generation of excess free radicals, reduce their concentration in membranes from peroxidation, and the protecting molecules exhibit hepatoprotective action [31-33]. Tannins initiate repair processes and improves the performance of antioxidant systems. In addition, licorice contains carotenoids that embed into the phospholipid-protein membrane structures exhibiting antioxidant activity. It is believed that the biological activity of bioflavonoids is due to their ability to inhibit the oxidation of ascorbic acid catalyzed by heavy metal ions, which form chelates with bioflavonoids. It is also believed that the bioflavonoids are able to inhibit cleavage of lipid peroxidation. Exceptionally important anthocyanins due to the charge on the oxygen atom in the ring of anthocyanins easily penetrate cell membranes [8,34].

\section{Source of Funding}

This research was supported by the Far Eastern Federal University (Project No. 14-08-06-10_и).

\section{References}

1. Zapadnyuk I, Zapadnyuk V, Zacharias E (1974) Laboratory Animals: Breeding, Maintenance, Use in Experiment. Kiev: Visha School, p. 303.

2. Vladimirov $U$ (2000) Biological membranes and unprogrammed cell death. Soros Educ Mag 9: T-6: 2-9.

3. Vengerovsky A, Markova I, Saratikov A (1999) Preclinical learning of hepatoprotective solutions. Pharmacol Committee News 2: 9-12.

4. Dorovskih V, Korshunova N, Krasavina N, Simonova N, Tikhanov V, et al (2006) Adaptogens and Cold Stress: Yesterday, Today and Tomorrow. Blagoveshchensk: DalGAU pp. 214

5. Dobryakov Y, Brehman I (1996) Search Natural Sources of Physiologically Active Matter in Offshore Organisms. Valeology: Diagnostics Tools and Practice for Health Security, Vol. 3. Vladivostok: Dalnauka, pp. 83-89.

6. Zenkov N, Lankin V (2001) Oxidative Stress. The Biochemical, Pathophysiological Aspects. Moscow: Science/Interperiodika, p. 490.

7. Zorikova S, Korotkov I, Zorikov P (2010) Wound Healing Activity in the Plants Containing the Flavonoids. Nat Tech Sci 3: 152-160.

8. Kurakin V, Kulagin O, Dodonov N, Tsareva A, Avdeeva EV, et al. (2008) Antioxidant activity of some tonic and hepatoprotective phytopreparations containing flavonoids and phenylpropanoids. Veg Resource $1 \mathrm{~T}$.44: 122-130.

9. Saratikov A, Vengerovsky A, Chuchalin V (2000) Extract of Halophytes collina (Lohein) - Effective Liver Protection. Tomsk: «STT».

10. Poznyakovsky V (2007) Concentrated basics of soft beverages with different functional. The new development. Beer Beverages 1: 32 .
11. Martinson E (2004) Prospects of production biologically active drugs from wild rosehip fruits. Storage Process Agric Raw Mater 8: 50-52.

12. Maksimets V (1988) Drinks Quality Control. Moscow: Economics, p. 96.

13. Wang J, Zhou C, Tian J, Sun N, Che H, et al. (2013) The analysis of specific allergenicity of food allergens families. Food Agric Immunol.

14. Shubina $\mathrm{O}$ (2000) Functional additives in beverages. Food Ind 5: 26-28.

15. Gardner C, Wylie-Rosett J, Gidding SS (2012) Nonnutritive sweeteners: current use and health perspectives: a scientific statement from the American Heart Association and the American Diabetes Association. Diabetes Care 35: 1798 1808.

16. Talabaeva S, Kadnikova I, Sokolova V, Podkorytova A (2001) The study of physicochemical properties of carrageenan extracts from red algae CHONDRUS ARMATUS. Izvestiya TINRO, T 129: 228-230.

17. (1992) Terms of preclinical safety evaluation of pharmacological agents (GLP): Steering normative document. Moscow: Medicine, pp. 78.

18. Bartosz G, Janaszewska A, Ertel D, Bartosz M (1998) Simple determination of peroxyl radical-trapping capacity. Biochem Mol Biol Int 46: 519-528.

19. Buege JA, Aust SD (1978) Microsomal lipid peroxidation. In: Fleischer S Packer L, eds. Methods in Enzymology. Cambridge: Academic Press, pp. 302 310.

20. Castaldo D, Laratta B, Loiudice R, Giovane A, Quagliuolo L (1997) Presence of residual pectin methylesterase activity in thermally stabilized industrial fruit preparations. Lebensm Wiss U Technol: 30: 479-484.

21. Ashurst PR (1998) Chemistry and Technology of Soft Drinks and Juices Sheffield: Sheffield Academic Press.

22. Giovane A, Laratta B, Loiudice R, Quagliuolo L, Castaldo D (1996) Determination of residual pectin methylesterase activity in food products. Biotech Appl Biochem 23: 181-184.

23. Lahaye M (1997) Seaweed dietary fibers: structure, physico-chemical and biological properties relevant to intestinal physiology. Sci Aliments 2: 563-584.

24. Khaitov R (1995) Ecological Immunology. Moscow: VNIRO, pp. 219.

25. Shigina $E$ (2007) A new approach to the problem of obtaining functional beverages with antioxidant action. Beer Beverages 4: 17.

26. Fomenko O (2002) Health problems in the XXI Century. Nutr Questions 3: 34 35.

27. Tateda K (1995) Potential activity of carrageenen to enhance antibacterial hostdefense system in mice. $\mathrm{J}$ Infect Chemother 1: 59-63.

28. Van T (2005) Anticancer activity of fucoidan from the vietnamese brown seaweed Sargassum mcclurei. Marine Ecosystems algae, invertebrates and products their processing, Arkhangelsk, pp. 364-368.

29. Ash M, Ash I (1995) Handbook of Food Additives. Brookfield, VT: Gower.

30. Imeson A, ed. (1994) Thickening and Gelling Agents for Food Industry. London: Blackie Academic \& Professional.

31. Whistler R, BeMiller J (1997) Carbohydrate Chemistry for Food Scientists. St Paul, MN: Eagan Press.

32. Krasnova N (1998) Development of pectin for preventive nutrition. Food Ind 1 11-12.

33. Spirichev V (2001) Food products enrichment by vitamins and mineral substances. Novosibirsk: Edition of Siberia University pp. 548.

34. Ohshima T (1998) Recovery and use of nutraceutical products from marine resources. Food Technol 52: 50-55. 